\title{
Pure human minigastrin: secretory potency and disappearance rate
}

\author{
HAILE T. DEBAS, JOHN H. WALSH, AND MORTON I. GROSSMAN1 \\ From the VA Wadsworth Hospital Center and UCLA School of Medicine, Los Angeles, California
}

SUMMARY Minigastrin, a gastrin with 13 amino-acid residues, was recently isolated from tissues by Gregory and Tracy (1974). In this study, pure human natural nonsulphated minigastrin (HG-13-I) and pure human natural nonsulphated heptadecapeptide gastrin (HG-17-I) were compared with regard to acid-stimulating potency and rate of disappearance from blood. Three dogs with gastric fistulae and Heidenhain pouches were given these gastrins by continuous intravenous infusion in doses of $100,200,400$, and $800 \mathrm{pmol} / \mathrm{kg}$-hr. Equimolar infusion rates of HG-13-I and HG-17-I caused equimolar increases over basal of serum immunoreactive gastrin but HG-13-I- was less than half as potent as HG-17-I in stimulating acid secretion (potency ratio $0.4,95 \%$ confidence limits 0.2 to 0.6 ). The half time for disappearance of $\mathrm{HG}-13-\mathrm{I}$ from blood was 1.8 minutes and its volume of distribution was calculated to be $0.171 / \mathrm{kg}$, values similar to those found for HG-17-I in an earlier study. The role of minigastrin in health and disease awaits further study.

Minigastrin, a gastrin with 13 amino acid residues corresponding to the carboxy-terminal part of the larger gastrins, has been isolated in both sulphated and nonsulphated forms from gastrinomas by Gregory and Tracy (1974). On gel filtration of human serum on Sephadex G-50 an immunoreactive component with the same elution volume as minigastrin has been found by Rehfeld and Stadil (1973), thus suggesting that minigastrin is one of the circulating forms of gastrin.

We (Walsh, Debas, and Grossman, 1974a) have proposed that the gastrins of known structure be designated by the number of amino-acid residues they contain, by their species of origin, and by the presence (II) or absence (I) of sulphation of the tyrosine residue. Thus nonsulphated human minigastrin, the subject of this study, would be designated HG-13-I.

The purpose of this study is to compare HG-13-I and HG-17-I with respect to gastric acid stimulation and rates of disappearance from the circulation.

\section{Methods}

GASTRINS

HG-13-I and HG-17-I were the kind gifts of Pro-

\footnotetext{
${ }^{1}$ Please address correspondence to Dr M. I. Grossman, VA Wadsworth Hospital Centre, Bldg 115, Room 115, Los Angeles, California 90073.

Received for publication 29 May 1974
}

fessor R. A. Gregory and Dr H. J. Tracy, University of Liverpool, who prepared them from a gastrinsecreting tumour of the Zollinger-Ellison variety (Gregory and Tracy, 1974). The gastrins were dissolved in $0 \cdot 1 \mathrm{M} \mathrm{NH} \mathrm{NH}_{4} \mathrm{OH}$ in concentrations of about $50 \mathrm{nmol} / \mathrm{ml}$. The molar concentration of gastrin in the solutions was calculated by dividing the absorbence at $280 \mathrm{~nm}$ by the extinction coefficient calculated (Wetlaufer, 1962) as the sum of the products of the number of residues of tryptophan and tyrosine per molecule times the respective extinction coefficients of these amino acids (Mihalyi, 1968). HG-17-I contains two residues of tryptophan and one of tyrosine per molecule giving a calculated extinction coefficient of 12261 and HG-13-I contains one residue of tryptophan and one residue of tyrosine per molecule giving a calculated extinction coefficient of 6884 .

\section{ANIMALS}

Three dogs with gastric fistulae and Heidenhain pouches were used for the study of biological activity. Half-time studies were done in these three and in an additional four dogs with similar surgical preparations. The surgery was done nine to 30 months before these studies were started.

\section{EXPERIMENTS}

The animals were deprived of food but not water for 18 hours before each test. The interval between 
tests was at least 48 hours. Harvard syringe pumps were used to maintain throughout each test a continuous infusion of $25 \mathrm{ml} / \mathrm{hr}$ of $0.15 \mathrm{M} \mathrm{NaCl}$ into a polythene cannula inserted into a leg vein. Stimulants were added to the saline infusion in amounts needed to give the required doses. The doses studied were $100,200,400$, and $800 \mathrm{pmol} / \mathrm{kg}$ hr. Starting with the lowest dose, each dose was given for $\mathbf{4 0}$ minutes; the dose was then doubled, and this doubling every $\mathbf{4 0}$ minutes was continued until the highest dose had been given.

Gastric juice was collected continuously from the gastric fistula and Heidenhain pouch and separated into 10-minute samples during infusion of gastrin. Volume was measured to the nearest $0 \cdot 1 \mathrm{ml}$, and acid concentration was determined by titrating $0.2 \mathrm{ml}$ samples with $0.2 \mathrm{M} \mathrm{NaOH}$ to $\mathrm{pH} 7$ on an automatic titrator (Radiometer, Copenhagen). The response was expressed as the mean of the last two 10-minute collections for each dose.

Two basal blood samples, 15 minutes apart, were obtained before starting gastrin infusions. Blood samples were taken 15 and 25 minutes after the start of the infusion of each dose of gastrin. Serum was separated and stored at $-20^{\circ} \mathrm{C}$. The gastrin concentration in all samples was measured by radioimmunoassay as previously described (Stern and Walsh, 1973). The antibody used for these assays was no. 1296 (Walsh, Trout, Debas, and Grossman, 1974b).

In preliminary studies, the immunoreactivity of HG-13-I was found to be $60 \%$ of that of HG-17-I. This difference in immunoreactivity did not affect the measurements because serum gastrin for each test was expressed in terms of a standard made from the gastrin infused in that test.

For the half-time studies, HG-13-I was infused into seven dogs at a dose of $1000 \mathrm{pmol} / \mathrm{kg}$-hr for 20 minutes. Blood samples were taken before the start of the infusion, at 10, 18, and $20 \mathrm{~min}$ after starting the infusion, and every two min after the infusion was stopped until acid secretion returned to basal levels. Basal gastrin concentration was subtracted from all values. Plateau serum gastrin values were taken as the mean of the values obtained at 18 and 20 min after starting the infusion. All postinfusion values were expressed as a percentage of the plateau value for each test on each dog. The mean percentage values for the seven dogs for each time period were calculated and used in the following linear regression analysis: $y=a+b x$ where $y$ is the natural logarithm of the mean serum gastrin expressed as a percentage of the plateau value, $a$ is the zero time intercept, $b$ is the slope (the absolute value of $b$ is the disappearance rate constant, $\mathrm{k}$ ), and $x$ is the time in minuces. The half time was calculated from the relation: $t_{1 / 2}=$ $0 \cdot 693 / \mathrm{k}$

The volume of distribution was calculated by the use of the plateau principle described by Goldstein, Aronow, and Kalman (1968) from the equation $\mathrm{V}=\mathrm{D} / \mathrm{Gk}$ where $\mathrm{V}$ is the volume of distribution in $1 / \mathrm{kg}, \mathrm{D}$ is the dose of gastrin in $\mathrm{pmol} / \mathrm{kg}-\mathrm{min}$, $\mathrm{G}$ is the plateau serum gastrin in $\mathrm{pmol} / 1$, and $\mathrm{k}$ is the rate constant described above.

Clearance of gastrin was calculated from the equation: $C=D / G$ where $C$ is clearance in $1 / \mathrm{kg}$-min and $D$ and $G$ have the same meanings as described above.

\section{Results}

\section{ACID STIMULATION}

HG-13-I was clearly less potent than HG-17-I in stimulating acid secretion (figure 1). Since the data

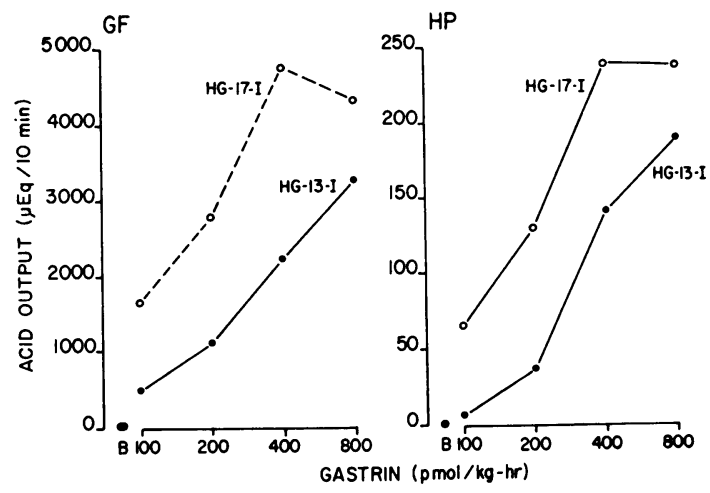

Fig 1 Dose response curves obtained with equimolar doses of HG-13-I and HG-17-I in three dogs with gastric fistula and Heidenhain pouch.

did not fit the Michaelis-Menten model satisfactorily, the comparison of potency was made by using the $3+3$ dose parallel line assay (Colquhoun, 1971). The responses to 100,200 , and $400 \mathrm{pmol} / \mathrm{kg}$-hr of HG-17-I were compared with responses to 200,400, and $800 \mathrm{pmol} / \mathrm{kg}-\mathrm{hr}$ of HG-13-Iand the molar potency ratio was expressed in terms of HG-17-I taken as the

\begin{tabular}{|c|c|c|c|}
\hline & Potency Ratio & Lower Limit & Upper Limit \\
\hline $\begin{array}{l}\text { Heidenhain pouch } \\
\text { Gastric fistula }\end{array}$ & $\begin{array}{r}0.42 \\
0.32\end{array}$ & $\begin{array}{l}0.30 \\
0.20\end{array}$ & $\begin{array}{l}0.57 \\
0.48\end{array}$ \\
\hline
\end{tabular}

Table I Molar potency ratio and $95 \%$ confidence limits of HG-13-I and HG-17-I for gastric acid secretion ${ }^{1}$

${ }^{1}$ Analysis of variance showed that both assays were valid as indicated by insignificant deviations from parallelism, linearity, and curvature. 


\begin{tabular}{|c|c|c|c|c|}
\hline \multirow[t]{2}{*}{ Infusion Rate (pmol/kg-hr) } & \multicolumn{2}{|c|}{$\Delta$ Gastrin $($ fmol/ml $)$} & \multicolumn{2}{|c|}{ Clearance (ml/kg-min) } \\
\hline & $H G-13-I$ & $H G-17-I$ & $H G-13-I$ & $H G-17-I$ \\
\hline $\begin{array}{l}100 \\
200 \\
400 \\
800\end{array}$ & $\begin{array}{r}19 \\
43 \\
92 \\
176\end{array}$ & $\begin{array}{r}14 \\
44 \\
101 \\
185\end{array}$ & $\begin{array}{l}88 \\
78 \\
72 \\
76\end{array}$ & $\begin{array}{r}119 \\
76 \\
66 \\
72\end{array}$ \\
\hline $\begin{array}{l}\text { Linear regression } \\
Y \text { intercept } \\
\text { slope } \\
\text { correlation coefficient }\end{array}$ & $\begin{array}{c}-1.43 \\
0.224 \\
0.999\end{array}$ & $\begin{array}{r}-4.75 \\
0.242 \\
0.996\end{array}$ & & \\
\hline
\end{tabular}

Table II Increment in serum gastrin over basal and clearance rates at various rates of infusion of HG-13-I and HG-17-I

standard (table I). On a molar basis, HG-13-I was 0.42 times as potent as HG-17-I based on Heidenhain pouch responses and $\mathbf{0 . 3 2}$ times as potent based on gastric fistula responses.

\section{INCREMENT IN SERUM DURING GASTRIN} INFUSIONS

Equimolar infusions of HG-13-I and HG-17-I

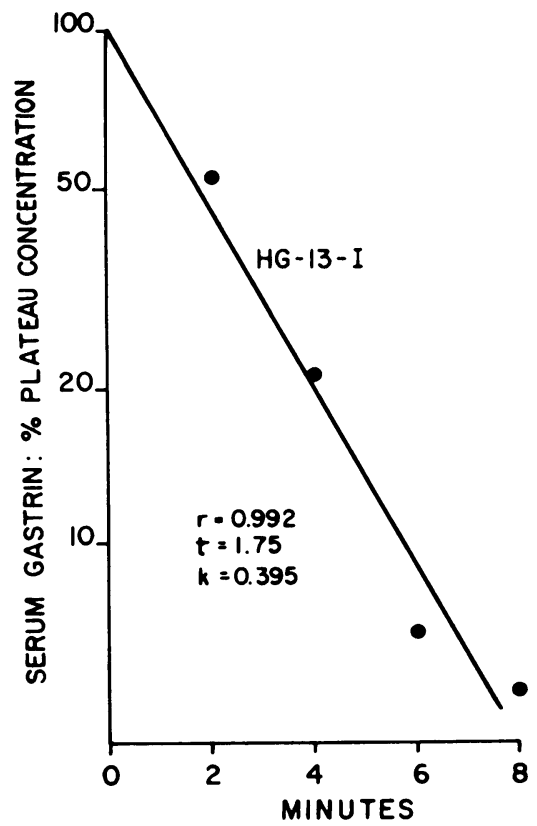

Fig 2 The rate of disappearance from the circulation of immunoreactive gastrin when intravenous infusion of 1000 pmol/kg-hr of HG-13-I for 20 min was stopped. Steady state concentration before stopping the infusion is taken as $100 \%$ after subtracting basal gastrin concentration. Postinfusion values are normalized to the steady state concentration. Half-life was calculated from disappearance constant obtained by linear regression analysis of natural logarithm of normalized concentration versus time. caused similar molar increases over basal in serum immunoreactive gastrin (table II). Basal gastrin, which has been shown to be mainly 'big-big' (Yalow and Wu, 1973), was subtracted from each value on the reasonable assumption that neither its molecular form nor its amount changes during the infusion period. The increment in serum gastrin was linearly related to the dose of gastrin for both HG-13-I and HG-17-I and the slopes of these lines did not differ (table II). The linear relation between dose and plateau serum level indicates that the rate of disposal of these gastrins did not vary with dose over the dose range studied. The similarity of the slopes for the two gastrins indicates that they have similar rates of disposal.

\section{CLEARANCE RATES}

Clearance rates, calculated by dividing the dose infused by the plateau blood level of gastrin, were similar for the two gastrins. The mean value for HG-13-I was $79 \mathrm{ml} / \mathrm{kg}$-min and for HG-17-I it was $83 \mathrm{ml} / \mathrm{kg}$-min (table I).

\section{SERUM GASTRIN HALF-TIME}

HG-13-I was rapidly removed from the circulation and was virtually undetectable six to eight min after stopping the infusion (figure 2). The calculated halftime was 1.75 minutes.

\section{Discussion}

Minigastrin is the latest member of the growing family of gastrins (Rehfeld, 1973): 'little' gastrin (17 amino-acid residues), 'big' gastrin (33 aminoacid residues), and 'big-big' gastrin and 'component I' whose structures are still to be determined. Structurally minigastrin is heptadecapeptide gastrin without the N-terminal tetrapeptide. Gregory and Tracy (1974) have recently isolated the sulphated and nonsulphated forms of minigastrin in pure form from gastrinoma tissue. Rehfeld and Stadil (1973), in gel filtration studies of immunoreactive gastrin in serum from patients with gastrinomas, 
found a pair of small presalt peaks with elution volumes similar to those of the minigastrins.

This study has shown that HG-13-I is less than half as potent as HG-17-I in its ability to stimulate gastric acid secretion. Since equal rates of infusion of the two gastrins cause equal increments in serum gastrin, the lower potency of HG-13-I is equally apparent whether one defines 'potency' in terms of exogenous dose or of serum concentration, ie, 'endogenous dose'. A strikingly different set of relationships exists when HG-17-I is compared with human nonsulphated big gastrin (HG-34-I) (Walsh et al, 1974a). In the latter case, while HG17-I and HG-34-I appear to have similar potencies when only exogenous doses are considered, HG-17-I is five times more potent when circulating concentrations are compared. This is so because when these two gastrins are infused at equimolar rates, HG-34-I achieves a much higher increment in serum concentration owing to the slow rate of its elimination from the circulation. These observations indicate the need for circumspect interpretations of total serum gastrin concentrations and underscore the potential usefulness of antibodies with specificity for the various molecular forms of gastrin. Only when we can readily measure the different gastrin fractions in the serum will we be able to compare meaningfully serum gastrin levels with acid secretion.

The half-time for disappearance of immunoreactivity from serum was $1.75 \mathrm{~min}$ for HG-13-I from the present study and $2.9 \mathrm{~min}$ for HG-17-I from an earlier study (Walsh et al, 1974a). Similarly the space of distribution was $0.17 \mathrm{l} / \mathrm{kg}$ for HG-13-I in the present study and $0 \cdot 24 \mathrm{l} / \mathrm{kg}$ for HG-17-I from the same earlier study. Since the overall disposal rate as reflected in the plateau serum level was the same for HG-13-I and HG-17-I in the present study (table I), we think that these differences in calculated half-times and spaces of distribution are probably not significant but a study designed to compare them in the same animals would be needed to settle the question.

There are many unanswered questions about the different molecular forms of gastrin. Are they synthesized as separate molecules, or is only the biggest molecule synthesized and enzymatic degra- dation generates the smaller forms? If the latter is true, what activates the enzymatic process and does it take place in the cytoplasm or at the cell membrane? Are there selective mechanisms of release for individual types of gastrin? Are the relative potencies of the individual gastrins the same at various target organs? When 'little' or 'big' gastrin is infused into the circulation, is there conversion to 'minigastrin'? One predictable result of the discovery of these various species of gastrin will be to stimulate further basic and applied investigation.

This study was supported by a Veterans Administration senior medical investigatorship (Dr M. I. Grossman) and by a Peptic Ulcer Center grant, AM 17328, from the National Institute of Arthritis, Metabolism and Digestive Diseases. Dr Debas holds a fellowship from the Canadian Medical Research Council. The authors are grateful to $\mathrm{Mr}$ John Washington, Mr Raymond Melendez and Mrs Helen Wang for technical assistance.

\section{References}

Colquhoun, D. (1971). Lectures on Biostatistics. An Introduction to Statistics with Applications in Biology and Medicine. Clarendon Press, Oxford.

Goldstein, A., Aronow, L., and Kalman, S. M. (1968). Principles of Drug Action, p. 292. Harper and Row, New York.

Gregory, R. A., and Tracy, H. J. (1974). Isolation of two minigastrins from Zollinger-Ellison tumour tissue. Gut, 15, 683-685.

Mihalyi, E. (1968). Numerical values of the absorbences of the aromatic aminoacids in acid, neutral, and alkaline solutions J. chem. Engng Data, 13, 179-182.

Rehfeld, J. F. (1973). Gastrins in serum, Scand. J. Gastroent., 8, $577-583$.

Rehfeld, J. F., and Stadil, F. (1973). Gel-filtration studies on immunoreactive gastrin in serum from Zollinger-Ellison patients. Gut, 14, 369-373.

Stern, D. H., and Walsh, J. H. (1973). Gastrin release in post-operative duodenal ulcer patients: evidence for release of duodenal gastrin. Gastroenterology, 64, 363-369.

Walsh, J. H., Debas, H. T., and Grossman, M. I. (1974). Pure human big gastrin: immunochemical properties, disappearance half time and acid-stimulating action in dogs. $J$. clin. Invest., 54, 477-485.

Walsh, J. H., Trout, H. H., III, Debas, H. T., and Grossman M. I. (1974). Immunochemical and biological properties of gastrins obtained from different species and of different molecular species of gastrins. Endocrinology of the Gut. Edited by W. Y. Chey and F. B. Brooks, pp. 277-289. Slack, Thorofare, N.J.

Wetlaufer, D. B. (1962). Ultraviolet spectra of proteins and amino acids. Advanc. Protein Chem., 17, 303-390.

Yalow, R. S., and Wu, N. (1973). Additional studies on the nature of big big gastrin. Gastroenterology, 65, 19-27. 